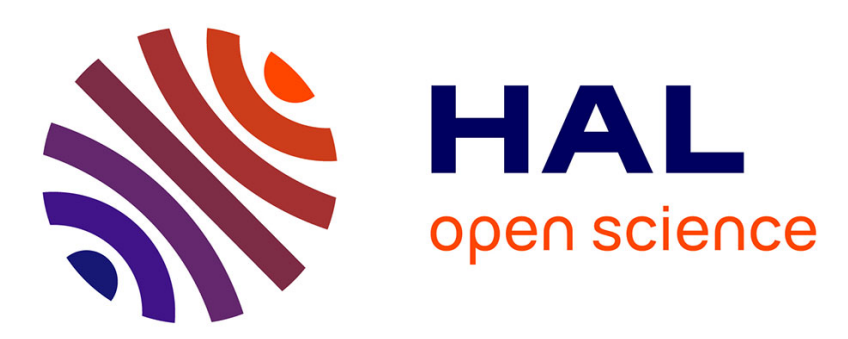

\title{
Industrial Applications with Cooperating Robots for the Flexible Assembly
}

Nikolaos Papakostas, George Michalos, Sotiris Makris, Dimitris Zouzias, George Chryssolouris

\section{To cite this version:}

Nikolaos Papakostas, George Michalos, Sotiris Makris, Dimitris Zouzias, George Chryssolouris. Industrial Applications with Cooperating Robots for the Flexible Assembly. International Journal of Computer Integrated Manufacturing, 2011, 24 (07), pp.650-660. 10.1080/0951192X.2011.570790 . hal-00712363

\section{HAL Id: hal-00712363 https://hal.science/hal-00712363}

Submitted on 27 Jun 2012

HAL is a multi-disciplinary open access archive for the deposit and dissemination of scientific research documents, whether they are published or not. The documents may come from teaching and research institutions in France or abroad, or from public or private research centers.
L'archive ouverte pluridisciplinaire HAL, est destinée au dépôt et à la diffusion de documents scientifiques de niveau recherche, publiés ou non, émanant des établissements d'enseignement et de recherche français ou étrangers, des laboratoires publics ou privés. 


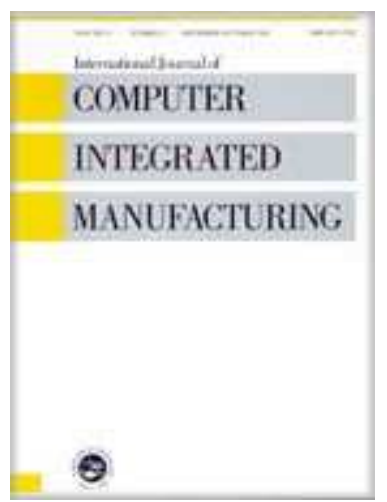

\section{Industrial Applications with Cooperating Robots for the Flexible Assembly}

\begin{tabular}{|r|l|}
\hline Journal: & International Journal of Computer Integrated Manufacturing \\
\hline Manuscript ID: & TCIM-2010-IJCIM-0076.R1 \\
\hline Manuscript Type: & Original Manuscript \\
\hline Date Submitted by the & 07-Feb-2011 \\
\hline Complete List of Authors: & $\begin{array}{l}\text { Papakostas, Nikolaos; University of Patras, Laboratory for } \\
\text { Manufacturing Systems and Automation } \\
\text { Michalos, George; University of Patras, Laboratory For } \\
\text { Manufacturing Systems and Automation } \\
\text { Makris, Sotiris; University of Patras, Laboratory for Manufacturing } \\
\text { Systems and Automation } \\
\text { Zouzias, Dimitris; University of Patras, Laboratory for } \\
\text { Manufacturing Systems and Automation } \\
\text { Chryssolouris, George; University of Patras, Laboratory for } \\
\text { Manufacturing Systems and Automation }\end{array}$ \\
\hline Keywords: & FLEXIBLE ASSEMBLY, ROBOTS, FLEXIBILITY \\
\hline Keywords (user): &
\end{tabular}

\section{SCHOLARONE \\ Manuscripts}




\title{
Industrial Applications with Cooperating Robots for the Flexible Assembly
}

\author{
Nikolaos Papakostas ${ }^{1}$, George Michalos ${ }^{1}$, Sotiris Makris ${ }^{1}$, Dimitris \\ Zouzias $^{1}$ and George Chryssolouris ${ }^{1 *}$ \\ ${ }^{1}$ Laboratory for Manufacturing Systems and Automation, Department of Mechanical \\ Engineering and Aeronautics, University of Patras, 26500 Rio, Patras, Greece.
}

*Corresponding author email: xrisol@1ms.mech.upatras.gr, Tel.: +30 2610997262 , Fax: +30 2610997744

\begin{abstract}
This paper discusses the key features of cooperating robotic cells in the automotive assembly, highlighting the key elements in the engineers' decision making process, while designing and implementing an assembly line for the Body In White (BIW). The main issues, affecting the performance of cooperating robotic cells, are discussed with the aid of a case study, where two different scenarios are compared. The first scenario uses a conventional fixture-based configuration of a robotic cell for performing a welding operation, while the second one features the use of cooperating robots. The cases are compared with the aid of a simulation platform and future potential developments are also discussed.
\end{abstract}

Keywords: flexible assembly; robots, flexibility

\section{Introduction}

In today's turbulent times, the automotive industry is in the middle of an incessant fight for balancing costs, time and quality constraints along with market demand: more customised vehicles and variants need to be produced, with fewer resources and materials, and in shorter cycles (Chryssolouris et al. 2008).

Flexibility is the key for achieving these goals and for adapting to the changes taking place in the market, in the society and in the global economic environment (Chryssolouris et al. 2006, Alexopoulos 2007, Georgoulias et al. 2009).

While the use of the automation technology, especially in the assembly lines, has reached a relatively high level of maturity, there is still much to be done for making existing resources and processes more flexible, in an effort to satisfy the market demand and the increasing need for higher customisation on an individual basis. Towards this direction the concept of flexible assembly has been introduced. 
The flexible assembly utilizes assembly robots and flexible part feeders in order to create a hybrid of manual, semi-automatic and dedicated assembly that is capable of small batch, large product variety production (Edmondson and Redford 2003). In this sense, a flexible manufacturing system (FMS) can be defined as a group of highly automated processing stations, such as robots, with tool change capabilities and a multi-processing plan of a complex synchronicity system, controlled by an integrated computer system. A flexible manufacturing cell (FMC) is the basic element of FMS, which consists of an automated material handling system and multi-purpose machines, usually robots (Chen 2010).

Nowadays, industrial robots have become an integral part of the automotive assembly lines due to their ability to accomplish specific tasks with improved speed, quality and reliability. Their flexibility heavily depends on how easy the changes of the end effectors and the modification or rewriting of the existing programs are. Due to their wide variety of capabilities, robots can be found in several different places inside a factory, working sequentially on the production line or in cells and preparing the sub assemblies that will be used later on, in the production line. The improvement in their performance and the decline in prices have promoted their use in many different applications. For instance, robots belonging to the current generation with 6 degrees-of-freedom (dof) are less expensive than 1-2 (dof) specialised equipment (Koeppe et al. 2005).

The latest trend in flexible robot cell development indicates that one of the primary objectives of equipment suppliers and systems integrators is to minimise the changeover and the overall passive times of robotic cells (Michalos et al. 2010). To this direction, the OEMs pursue the maximum reuse of the existing equipment, the extension of the existing resources' capabilities and the utilisation of the modern 
information technology. The design of robotic assembly cells is a research area, on each own, and it can be broken down to several problems such as (Chryssolouris 2006, Khouja et al., 2000):

- the resource requirements problem: This involves the determination of the appropriate quantity of each type of production resource (e.g. robots, grippers fixtures etc.) in the assembly system. The objective is usually cost-based, such as the maximization of investment efficiency, or time-based, such as the maximization of the production rate.

- the resource layout problem: In this case, the problem consists in locating a set of resources in a constrained floor space. The objective is typically to minimize some combination of material handling cost, travel time, and resource relocation cost (Aly et al., 2010).

- The material flow problem: The objective is to determine the configuration of a material handling system so that a combination of flexibility, cost, production rate, and reliability of the manufacturing system to be maximized.

\section{Cooperating robots for part assembly}

Cooperating robots, i.e. robots communicating with each other for carrying out common tasks, may expand their capabilities greatly. They can be used for reducing the number of required fixtures as well as for shortening the process cycle time, whilst addressing the accessibility constraints introduced by the use of fixtures (Ranky 2003). Their control is based either on the use of single controllers, which are capable of multi-tasking and controlling multiple robots or on the use of special frameworks, allowing standard controllers to cooperate with each other, by exchanging motion data, as well as synchronization and safety signals. This way, in a flexible cell, some of the welding spot robots may be involved in transportation activities and some others in workspace sharing or in collision avoidance. The cooperating robots' applications comprise characteristics, such as (Koeppe et al. 2005): 
- Workspace sharing: the definition of the critical workspace sections, where only one robot may be present at a time;

- Motion synchronisation: the capability of allowing multiple machines in a cell to begin and complete a motion command simultaneously;

- Program synchronisation: a feature allowing robot programs to remain at certain points until other programs (controlling other robots, machines or devices) have reached the same ones;

- Linked motion: a feature enabling multiple machines to handle a part at the same time.

A representative case of the cooperating robots' use, in the heavy truck

assembly process, is the assembly of different model cabs, each one featuring a

different type of sunroof (Wilson 1999): a robot line with five production cells and ten robots in total is utilised. The first two cells with two robots construct the floor pan. Another cell uses two robots to finish the floor. Finally, two identical cells of three robots assemble the main structure (Wilson 1999). Another case is that of using the laser welding technology for mounting the front end bumper module, of a family car, with the use of two cooperative robots: once measured and cut by the first robot, the plate is welded, while a second robot holds the mounting plate at the right place (Kochan 2004). An illustrative example follows in Figure 1 (Michalos et al. 2010) where two robots (in the middle and the right part of the figure) are picking up and holding the parts to be welded, while the third one (on the left) performs the spot welding operation. The same cell has been used in the scenario of the case study B in this paper.

[Please insert figure 1 here]

However, the adoption of the cooperating robots technology presents several challenges to be met such as coordination, sequencing, collision and communication architectures. Real time motion coordination and communication between robot controllers requires higher computational capabilities from the robot controller's side as well as protocols for high speed signal exchanging. The programming aspects of 
such systems are also characterized by higher complexity, since programmers need to consider the dynamic nature of real time communication between robots during the generation of code for the control of the robots. The direct, non supervised, interaction between robot controllers signifies that a very careful mapping and strict determination of the signals exchanging between the different robots, needs to be followed.

There are several paradigms with respect to the number of robots and control units: the controller of a single robot (Figure 2) can be used to manage the servo units of a group of robots. The programs are stored in the master controller and a single teach pendant is used for programming of all robots within the cell.

[Please insert figure 2 here]

A more complex configuration involves the communication between multiple robots that are individually controlled by separate controllers as shown in Figure 3. The types of robots and their controllers may vary but the structure of this architecture remains the same as long as the interfacing and communication requirements among the different types of controllers are met. These controllers exchange information among themselves via the Ethernet network in order to achieve the time and motion coordination. Nevertheless, there is substantial additional effort required for reducing the extensive programming work needed, in order for such systems to be viable in an industrial environment.

[Please insert figure 3 here] 


\subsection{Work cell design issues}

The improvement of a robotic work cell design is a continuously evolving field. The first attempts focused on the evolvement of every single sub-part of the cell (type of robots and mechanisms used, robot cooperation, work cell layout, etc.), while some of the latest ones consider the entire work cell as one unit. A few methods for comparing and evaluating different work cell designs had been proposed in the past.

One of the most important features in the automated assembly process is the cycle time. During the initial stages of a work cell' design, it is necessary that the time, required for the completion of a given assembly task, be estimated (Choi and Ip 1999). By analysing the entire welding process, in the two basic tasks, which consist of, i.e. a part reaching and the tool's centre point (TCP) moving, a better estimation of the cycle time may be obtained.

The effect that the gripper weight has on the motion cycle time is another important parameter that should be taken into account during the work cell design process. Increase in the weight of the gripper, also leads to the cycle time increase (Choi and Ip 1999). In many practical cases, minimising the gripper's weight is one of the most critical objectives in order for the work cell's throughput to be increased. In other cases, the existence of a big gripper's footprint (vertical projection of the gripper's fingers when open) could lead to unnecessary system delays due to the gripper being too big to reach the part. Other ways of increasing the throughput with a proper gripper design, are by minimizing the interference measure, chamfering the exterior of the gripper's fingers, grabbing many parts with one gripper or mounting many of them on a single robot (Causey 2003).

Nevertheless, achieving relatively small cycle times should not be the only concern of the design process. It has been proven that parameters such as those indicating how easy it is to assemble parts, how different or repetitive the movements 
are, the distance between the resources, the selection of part feeders for shortest travel distance and the careful choice of peripherals (e.g. feeders) with the aid of simulation environments for the creation of different assembly scenarios by one robot, can be as important as the cycle time. The structural capacity of a welding manipulator for flexible assembly is another important parameter. Welding manipulators usually require $6 \mathrm{DOF}$, when component insertions are performed from more than two directions and, at the same time, the use of an active fixture is recommended to manipulate the assembly, in order for excessive gripper changes to be avoided. Two parameters, namely the robot's speed and acceleration, should be carefully specified, since they directly affect both the system's cost and its repeatability (Edmondson and Redford and Dailami 1998). Although it would be expected that an increase in the acceleration would reduce the assembly's cycle time, the manipulator's cost should have also been taken into consideration and the resulting vibration problems could eliminate the benefits gained (Redford and Dailami 1998). The advantages of a maximum velocity should also be evaluated thoroughly, since short distances don't allow the TCP to reach it. Another design strategy is placing the fixtures at the centre of the manipulator work space so that robots can reach the parts from all directions. When part picking, placing and mechanical fastening could be performed, by the same manipulator, for the purpose of saving space, the manipulator velocity and acceleration were found to have a minimal effect on the overall assembly cycle time (Edmondson and Redford 2002).

In general, the use of multiple robots or multi-armed robotic equipment may lead to a reduction in the cycle time as well as in the improvement of the productivity, flexibility and quality, in comparison with the use of single robots. Multi armed work cells also provide distributed control at high speeds that help with problems of 
production control, such as scheduling and balancing robots in a cell, advanced layout design and simulation, at the planning and during the programming stages (Mahr 2000). In the case of multi-robot applications, different task sequence strategies are often identified, tested and validated with the help of simulation. Industrial practice has shown that there is no single strategy that can be used in all cases in order for the best performance to be achieved, and that the most effective task sequence strategy is a function of the noise in the system (Redford and Dailami 1998).

\section{A part assembly scenario}

The current practice in the automotive industry favours the use of the lowest possible number of robots. In fact, in most cases, fewer than eight robots are part of a single work cell. Nevertheless, most work cells consist of multi-task robots, capable of performing two to usually three tasks, with welding and handling being the most popular. Furthermore, one of the major objectives of the work cell design is to minimise the use of fixtures in the assembly stages for limiting the overall cost as well as for increasing flexibility.

\subsection{Description of cases}

This paper presents the investigation results regarding the effect that the number of fixtures and the robots' cooperative motion have on the production's cycle time. Two cases, inspired by the automotive assembly industry and more specifically the assembly of components belonging to the Body In White of a vehicle, were therefore developed. The two components being assembled in the cell are part of a vehicle body side and are shown in Figure 4 in green and yellow colours respectively.

[Please insert figure 4 here]

- The first case (case A) represents a simplified version of an industrial work cell from a BIW assembly stage, where two robots work sequentially in order to produce the left pillar of the car frame as shown in Figure 5. One robot (R1) 
is grabbing in sequence the two BIW parts from the fixtures F1 and F2. Following, it places the parts on fixtures F3 and F4 respectively and the second robot (R2) performs the spot welding operation. Finally, the robot R1 picks the assembled components and places them on fixtures F5 and F6 so that they can be removed from the cell. In this case, no cooperative motion is carried out, which, however, means that an increased number of fixtures will have to be used;

- The second case (case B) features a cell that produces the same BIW components, but it is constructed with three cooperating robots for performing the spot welding operation (Figure 6). Two of the robots (R1 and R3) are assigned to the manipulation tasks, while the third (R3) performs the welding. Apparently, the assembly of the second case leads to the reduction of the number of fixtures (denoted by $\mathrm{F}$ in Figures 5 and 6 ) used in the process.

[Please insert figure 5 here]

[Please insert figure 6 here]

For both cases, a specific type of robot with 6 DOF is used for all positions; this type may use four different axes constraints for defining the motion of the Tool Centre Point (TCP). This makes it quite flexible for accomplishing different tasks and gives a great variety of options to study as long as the motion type is concerned. With respect to the control schemes presented in Figures 2 and 3, they were not included in the simulation model since only the kinematics of the mechanisms were of interest in the current study. Nevertheless, if the cases were to be deployed in actual industrial environments, it could be stated that the one of Figure 2 would seem more appropriate for this assembly task, due to the smaller programming effort requirements. Should the assembly task involve more complex operations in terms of real time communication and cooperation (not simple synchronization of the movements) the control scheme of Figure 3 would be more efficient.

The different BIW part geometries made it necessary to use two different types of fixtures, namely type $\mathrm{P} 1$ for part 1 and type $\mathrm{P} 2$ for part 2.In this paper, the primary research objective is the study of the effect the number of fixtures and the cooperative 
type of motion have on the cycle time. For this reason, both cells are similarly designed with robots performing common tasks in the two cases, in about the same relative distances with the others, since it is preferable to avoid the different travel distance of the TCP, due to different robot positions. If this aspect is neglected, the travel path of the correspondent TCPs in the two cases will differ, and as a result, the cycle time of the whole process will be different too. This way, it will be harder to analyse the effect the additional fixtures have in the cell's cycle time (when robotic cooperation is not used). On the other hand, the additional fixtures that are used in the sequential case require more space and the relative positions between robots cannot remain exactly the same in the two cases, primarily due to the fact that collisions have to be avoided.

The layouts for both cases are depicted in Figures 5 and 6. Each circle in both pictures represents a robot. The big rectangles represent the bases, where fixtures stand. The small ones represent the two types of fixtures used, corresponding to part types P1 and P2. The difference between the two cases is apparent: at the centre of the layout of case A (Figure 5), a base with two more fixtures has been added, compared to the layout of case B (Figure 6), where a robot has taken their place. The main difference between these cases is that in case A, the handling of the parts during the welding operation, is carried out with the aid of the two fixtures at the top, while in case B, robots 1 and 2 perform all the other handling tasks during the process. The base at the top and the two additional fixtures are missing from Figure 6, since, robots 1 and 2 hold the parts before and during the handling process. The installation of the second handling robot could presume the use of another base for it, depending on the type of the robot. Nevertheless, the base is usually supplied by the robot via the equipment provider but represents a small portion of the cost pie (Forge et al., 2010). 
The robot itself, the tooling and the programming costs constitute about $80 \%$ of the total investment cost. The same holds for the bases used for supporting the fixtures in each one of the two case studies. In case B, robot 1 will pick the first part and robot 2 the other one. Robots 2 and 3 perform the welding process in cases A and B respectively. The fixtures on the right (F1 and F2) and on the left (F5 and F6) of robot 1 are the first and last positions of the parts. Robots 1 and 3 are placed in a similar position (case B) to the robots of the traditional cell (case A). Furthermore, the two fixtures, which are replaced by robot 2 in case B, are placed inside the working envelope of robots 1 and 2 in case A. This way, the two fixtures may be used for the handling task, which would be performed by the cooperating robots' grippers in the same position, in case $\mathrm{B}$.

\subsection{Case study modelling and simulation}

Both cases described in the previous section have been simulated with the aid of the Dassault Systems' simulation package. For each case study, a simulation model, which involves the geometric and kinematic data for all devices including robots, fixtures, grippers and parts, has been created. The models allow for the estimation of the gripper and fixtures' opening and closing time as well as the movement duration of each robot. The models use realistic speed and acceleration profiles for all the mechanisms, in order to provide a highly detailed representation of the actual equipment's behaviour within the digital model. All time estimations in this work have been derived from these simulation models.

In the first case (case A), all robotic tasks are performed sequentially, one right after the other. The operations, taking place in case A, are shown in Figure 7. Robot 1 picks, lifts and places Part 1 (Operation1-4) and then picks, lifts and places Part 2 (Operation 5-8) in the welding position. Robot 2, welds the parts in their welding 
position (Operation 9). In the end, robot 1 moves the assembly to its final position (Operation 10-14) and returns to the home position (Operation 15). The corresponding fixtures are synchronised with the robotic moves, so that the release and picking of the parts occur in a timely manner.

\section{[Please insert figure 7 here]}

\section{[Please insert figure 8 here]}

The operations, taking place in case B, are shown in Figure 8. Robots 1 and 2 pick and handle Part 1 (Operation 1,6) and Part 2 (Operation 2, 7) respectively, in the welding position. In the meantime, Robot 3 is removed so that Robots 1 and 2 may move towards the welding position. Robot 3 performs the welding operation of the two parts (Process8). The next part Robot 2 drops Part 2 (Process9). The welded part is then placed to its final position (Operation 10,13) by Robot 1. The next step (not included in this particular case) is the transportation of the assembly (welded Parts 1 and 2) to the next station, so that Fixtures F2 and F3 get ready for the next cycle. The corresponding fixtures are synchronised with the moves of all 3 robots, so that the release and holding of the parts occur in a timely manner.

\subsection{Development of alternatives}

For both cases, a series of alternatives were developed. Different design parameters could be used for developing these alternatives, starting from the initialisation of the layout design process, such as:

- Different types and numbers of robots, fixtures, grippers;

- The exact position of each robot in the cell;

- Motion design (linear or interpolated).

Similarly, a set of different criteria could be utilised for evaluating these alternatives, including: 
- Cost;

- Flexibility;

- Quality of assembly process;

- Cycle time;

- Overall length of the robotic motion.

In order to focus on the difference between a fixture-based and a fixtureless assembly in terms of the overall cycle time, the study in this paper, is limited to the cycle time of both cases described above.

It is, however, apparent that many different design parameters and criteria may be used in a similar problem

[Please insert figure 9 here]

The overall process as depicted in Figure 9 includes the basic steps that should be followed in order for a solution to be reached for a specific assembly problem. After specifying the details of the problem and identifying the design parameters and the constraints, different alternatives, based on different sets of values of the design parameters, may be generated. The alternatives using different criteria, are evaluated and the best alternative may then be selected and fine-tuned by the design engineer. The next step includes the realisation of the proposed alternative solution, which may then be used again in a similar problem or it may be modified for addressing a different problem.

\subsection{Results}

The two cases (case A and case B) were simulated and the design and performance differences between them are summarised in Table 1, where it is shown that the overall cycle time is reduced by $49 \%$ in case $B$.

[Please insert table 1 here] 
The basic difference between cases A and B is the reduced number of operations in the latter, although a third robot is introduced to the cell. Furthermore, the steps required for synchronising the operations are reduced to 8 in case B. This is one of the main reasons for reducing the overall cycle time by $49 \%$.

In particular, in case $\mathrm{A}$, the time required for the fixtures to open and close, so that the robots may handle and weld the parts, is added entirely to the overall cycle time. Moreover, the number of fixturing operations (open close) in case A are six (opening of F1, closing of F4, opening of F2, closing of F3, opening of F3 and F4, closing of F5 and F6) while in case B, there are only three (opening of F1, opening of F2, closing of F3). In addition to this and in order for the total time added to the cycle time, due to the fixturing operations to be calculated, the cooperative handling of the parts needs to be considered. In this case, the fact that the picking of parts by robots 1 and 3 (case B) is carried out in parallel, meaning that the opening times of the fixture are overlapping and therefore, the time added to the cycle time is less than the sum of the opening times of the two fixtures.

The opening and the closing speed of the fixtures in both cases is the same therefore, the difference is traced on the design of the cell's operation rather than on the individual equipment components that are used. As a result of the above, the time for the operation of the fixtures in case B is about two thirds of the respective time in case A.

Another important parameter, which should be taken into consideration, is the way that the robots' grippers are used and the number of times they open or close. In In the first case, there are three opening and three closing operations (six in total) for picking up and placing the two parts and the complete subassembly on the fixtures. The second case, involves only two closing operations of the robots R1 and R2 for 
picking up the parts from the fixtures, and two opening operations for R1 for releasing the subassembly after the welding, and R2 for releasing the subassembly on the last fixture. Therefore, the respective time for a gripper's operations is not the same in both cases. Finally, it has to be clarified that although another gripping operation is added to the newly introduced robot of case B, the operation is carried out in parallel with the gripping operation of the other handling robot (R2). This means that the time added to the cycle time, due to the operation of the gripper, (see also Table 1) is actually less than that for the duration of the actual gripping operation.

The presence of the third robot in case B, contributes also to the shortening of the cycle time by $4.088 \mathrm{sec}$, since the first robot in case A travels from the position it left part 1, to the starting position of part 2, which is to be handled next (Operation 5, Figure 7). The digital manufacturing software package has allowed for a high accuracy in estimating the movement time (up to thousandths of a second) and that is thanks to its capabilities of applying realistic speed and motion profiles to the simulated equipment. With the use of the cooperating robots in case B, both parts are handled separately and therefore, there is no need for spending time as it is in Operation 5 for case A.

It is obvious that the number and the type of the fixtures used have a great impact on the cycle time of the work cell. Although, for a single case, they are in principle more cost effective to use, compared with the introduction of a new robot, their presence in the work cell, also forms a constraint, since they have to be tackled as motion obstacles during the assembly process, in order to avoid collisions. Most of the times, their presence require longer TCP travels and therefore, result to longer cycle times. 


\section{Conclusions}

This paper discusses the use of cooperating robots in assembly processes, especially in the automotive industry and in the case of assembly of BIW components. Two cases are investigated: the first, following a conventional approach, utilises a pair of fixtures for holding two parts during the welding process, while the second one is based on the use of two robots for holding the parts and an extra robot for performing the welding process. Both approaches exhibit a series of advantages and disadvantages:

- The first case is less complicated in terms of the programming effort required for the control of the cell, since there is no motion synchronisation taking place;

- The first scenario, as a stand-alone case, is less expensive to implement, since, in principle, the fixtures cost less than robots do;

- In the long term, and especially in cases that the work cell is planned to be used for addressing different assembly configurations, the second layout is more flexible, as it demonstrates a more versatile list of handling and joining options;

- As the cost of robots is reduced and their specifications are improved, it is anticipated that cooperating robots will be used in a larger part of the corresponding industrial applications in the near future.

The investigation of both case studies has been carried out with the use of digital simulation models since an actual deployment in real life systems would require excessive effort, cost and implementation time. Nevertheless, the conclusions that were drawn from the simulated case studies have been utilized in the context of the implementation of a real fixtureless assembly cell. The cell is used for assembling the floor panel of the vehicle with the central tunnel of the floor with the use of cooperating robots.

In this study, the use of cooperating robots has been investigated from an operational point of view and it was focused on the cost and time implication of the technology. The analysis and simulation covered the cooperation of the robots to successfully carry out the assembly task but there were several technical issues to be 
addressed prior to the deployment of such cells and have been proposed as future work. More specifically, the control of cooperative systems is the main challenge since the current robot controllers are neither able nor optimized to support multiple robot coordination in real time. The technical integration of more than one robots, under the same controller, is translated into a greater degree of complexity since the control of the exchanged signals becomes dynamic and in some cases, unpredictable. For this purpose, the programming environments will have to be vastly improved, in order for more complex challenges and assembly setups to be addressed. Techniques such as offline programming and virtual commissioning can help investigate all these issues, but there is still a \gap in successfully simulating all control aspects of cooperating robots.

As far as joining technologies are concerned, the analysis of the suitability of cooperative processing is another research area to be addressed. The requirements of each process in terms of the parts' positioning accuracy, clamping forces etc. may not allow for mid-air parts processing due to the great weight of the required grippers and so forth.

Reducing cost, and improving flexibility, quality and production rates form a series of long-sought objectives for every manufacturing organisation around the world. The effective use of cooperating robots may prove critical towards that direction.

\section{Acknowledgements}

This work has been partially supported by the Integrated Project 'Flexible assembly Processes for the car of the third millennium - MyCar' (FP6-2004-NMP-NI-4-026631), funded by the European Commission.

\section{References}

Alexopoulos, K. , Papakostas, N. , Mourtzis, D. , Gogos, P., Chryssolouris, G., 2007. Quantifying the flexibility of a manufacturing system by applying the transfer 
function, International Journal of Computer Integrated Manufacturing, 20(6), $538-547$

Aly, M. F., Abbas, A. T., Megahed, S. M., 2010. Robot workspace estimation and base placement optimisation techniques for the conversion of conventional work cells into autonomous flexible manufacturing systems. International Journal of Computer Integrated Manufacturing, 23(12), 1133-1148.

Causey, G, 2003. Guidelines for the design of robotic gripping systems. Assembly Automation, 23(1), 18-28.

Chen, K.Y., 2010. Cell controller design for RFID based flexible manufacturing systems, International Journal of Computer Integrated Manufacturing, First published on: 07 December 2010 (iFirst), DOI: 10.1080/0951192X.2010.523845

Choi, C.K, Ip, W.H., 1999. A comparison of MTM and RTM. Work Study, 48(2), 5761.

Chryssolouris, G., 2006. Manufacturing Systems - Theory and Practice, 2nd Edition. New York: Springer-Verlag.

Chryssolouris, G., Papakostas, N., Mavrikios, D., 2008. A perspective on manufacturing strategy: Produce more with less. CIRP Journal of Manufacturing Science and Technology, 1, 45-52.

Dassault Systèmes, 2010, DELMIA® V5 R20 online documentation.

Edmondson, N.E, Redford, A.H., 2002. Selection of manipulator for flexible assembly system. Industrial Robot: An International Journal, 29(2), 162-169.

Edmondson, N. F., Redford, A. H., 2003. Simulation of a generic flexible assembly system. International Journal of Computer Integrated Manufacturing, 16(3), 157-172.

Forge, F., Blackman, C., A Helping Hand for Europe: The Competitive Outlook for the EU Robotics Industry, JRC Scientific and Technical Reports, 2010, ISBN 978-92-79-17657-9

Georgoulias, K. , Papakostas, N. , Mourtzis, D., Chryssolouris, G., 2009. Flexibility evaluation: A toolbox approach, International Journal of Computer Integrated Manufacturing, 22(5), 428 - 442

Khouja, M., Booth, E. D., Suh, M., Mahaney, J. K., 2000. Statistical procedures for task assignment and robot selection in assembly cells. International Journal of Computer Integrated Manufacturing, 13(2), 95 - 106.

Kochan, A., 2004. Volkswagen makes a success with lasers. Assembly Automation, 24 (4), 357-360.

Koeppe, R., Engelhardt, D., Hagenauer, A., Heiligensetzer, P., Kneifel, B., Knipfer, A., Stoddard, K., 2005. Robot-Robot and Human-Robot Cooperation in Commercial Robotics Applications, Robotics Research. Berlin Heidelberg: Springer Verlag.

Mahr, C., 2000. Beyond the standard cycle: increasing workcell productivity by optimizing robot placement and other key performance influences. Industrial Robot: An International Journal, 27(5), 334-337.

Michalos, G., Makris, S., Papakostas, N., Mourtzis, D., Chryssolouris, G., 2010. Automotive assembly technologies review: challenges and outlook for a flexible and adaptive approach. CIRP Journal of Manufacturing Science and Technology, 2 (2), 81-91. 
Ranky, G.P., 2003. Collaborative, Synchronous Robots Serving Machines and Cells. Industrial Robot An International Journal, 30(3), 213-217.

Redford, A.H., Dailami, F., 1998. Designing a generic flexible assembly system. Proceedings of the 8th International Conference on Flexible Automation and Intelligent Manufacturing, Portland, Oregon, USA.

Wilson, M., 1999. Vision system in the automotive industry. Industrial Robot: An International Journal, 26 (5), 354-357. 


\section{Figure Captions}

Figure 1. Cooperating robots performing spot welding on automotive parts (scenario $\mathrm{B}$ of the case studies)

Figure 2. Multiple robots interacting under a single controller

Figure 3. Multiple robots controlled and interacting under multiple controllers

Figure 4. Bodyside components assembled in the case studies

Figure 5. Layout of conventional work cell (case A).

Figure 6. Layout of the fixtureless work cell (case B).

Figure 7. Sequence of operations carried out in case A (with reference to Figure 2).

Figure 8. Sequence of operations carried out in case B (with reference to Figure 3).

Figure 9. Generic robotic cell design process. 


\begin{tabular}{|c|c|c|}
\hline & $\begin{array}{c}\text { Case } \\
\text { A } \\
\end{array}$ & $\begin{array}{c}\text { Case } \\
\text { B } \\
\end{array}$ \\
\hline Number of fixtures & 6 & 3 \\
\hline Number of robots & 2 & 3 \\
\hline Number of bases & 3 & 2 \\
\hline Fixture's total operation time $(\mathrm{sec})$ & 30 & 20 \\
\hline Time added to process because of the fixture operation (sec) & 30 & 10 \\
\hline Gripper operation time $(\mathrm{sec})$ & 4 & 4 \\
\hline Time added to process because of the gripper operation (sec) & 4 & 3 \\
\hline Time difference between part 1 and 2 handling to welding positions (sec) & 4.088 & 0 \\
\hline $\begin{array}{l}\text { Time added because of obstacles presence and average speed reduction, } \\
\text { compared to case B }(\mathrm{sec})\end{array}$ & 5.463 & - \\
\hline Overall time difference between the two cases (sec) & 30,551 & - \\
\hline Process cycle time (sec) & 62.269 & 31.718 \\
\hline
\end{tabular}

Table 1. Comparison of case A and case B. 


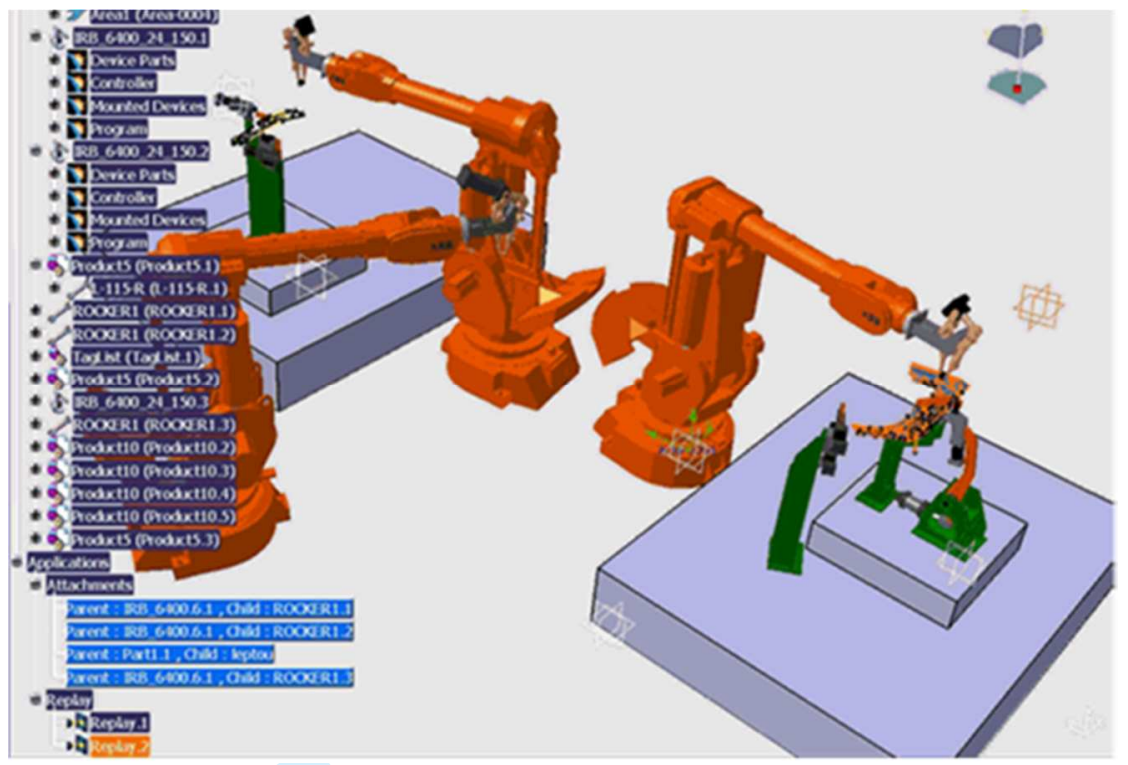

Figure 1. Cooperating robots performing spot welding on automotive parts (scenario $\mathrm{B}$ of the case studies)

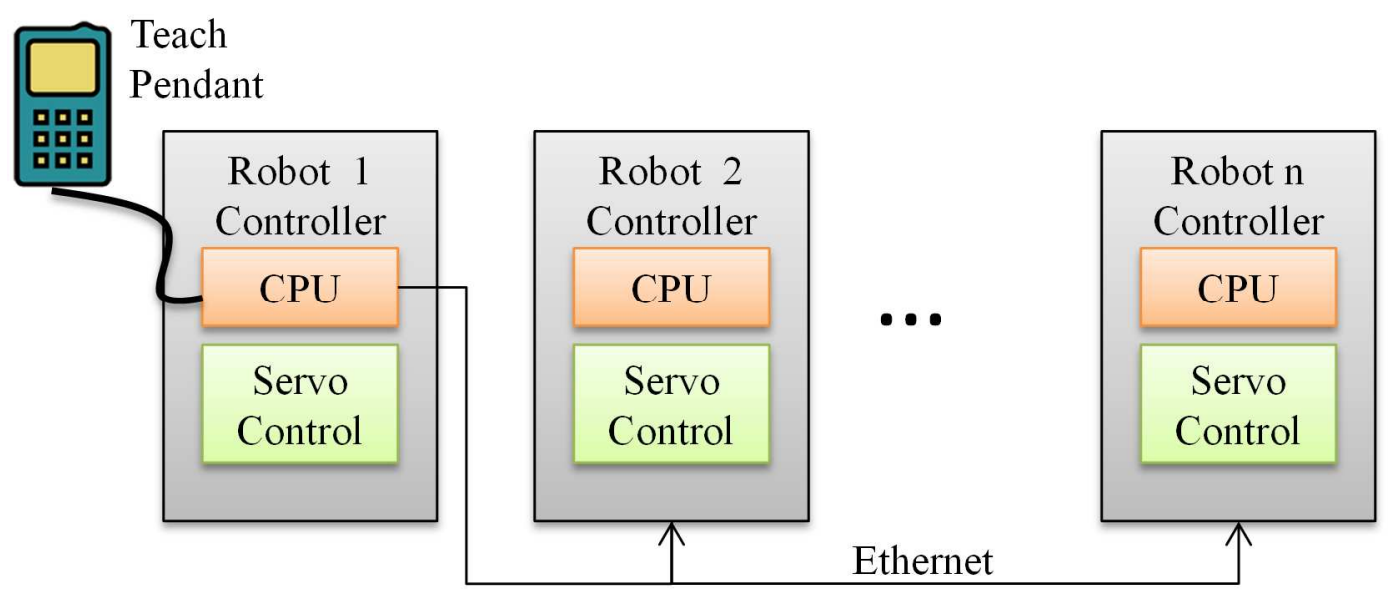

Figure 2. Multiple robots interacting under a single controller

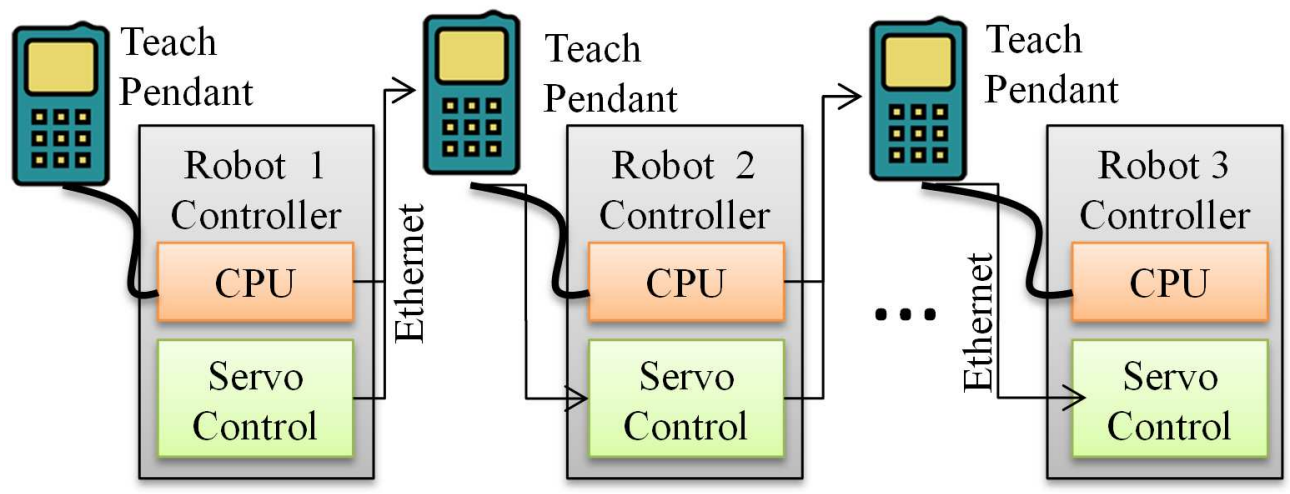

Figure 3. Multiple robots controlled and interacting under multiple controllers 


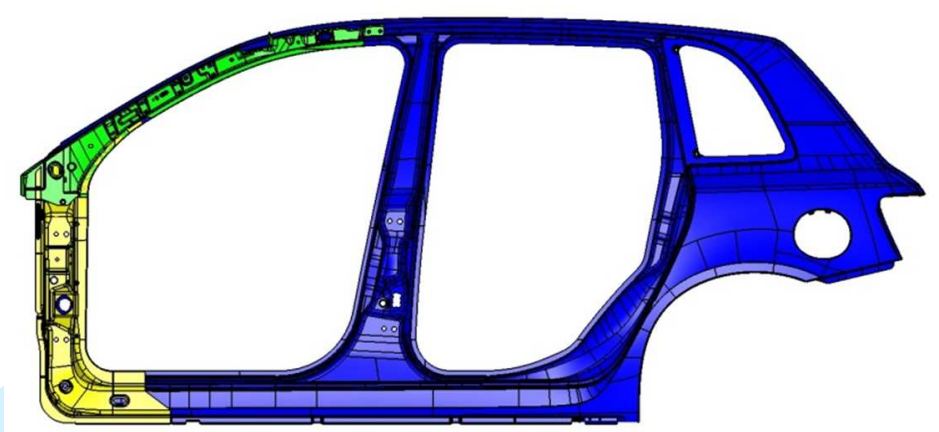

Figure 4. Bodyside components assembled in the case studies

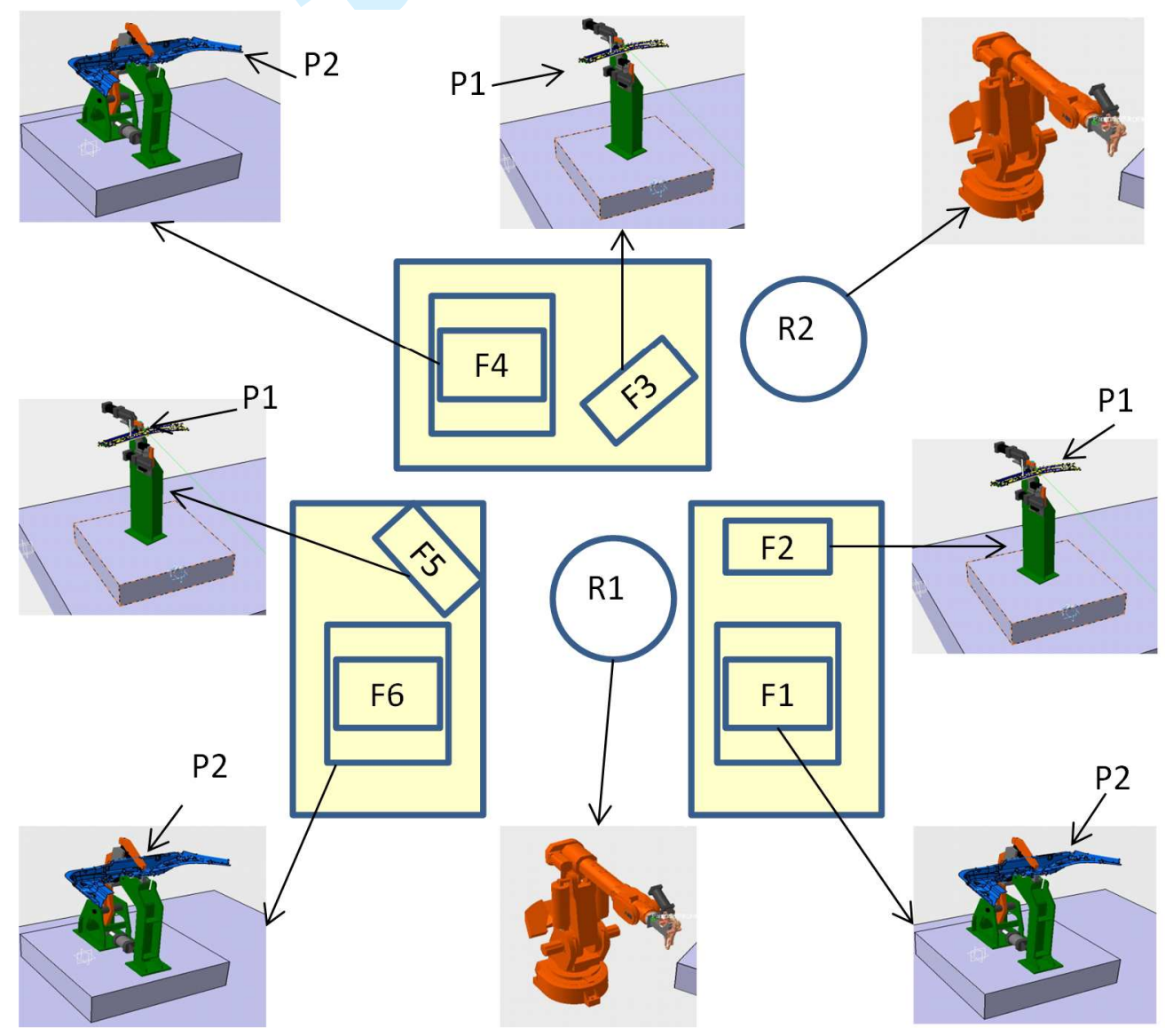

Figure 5. Layout of conventional work cell (case A). 


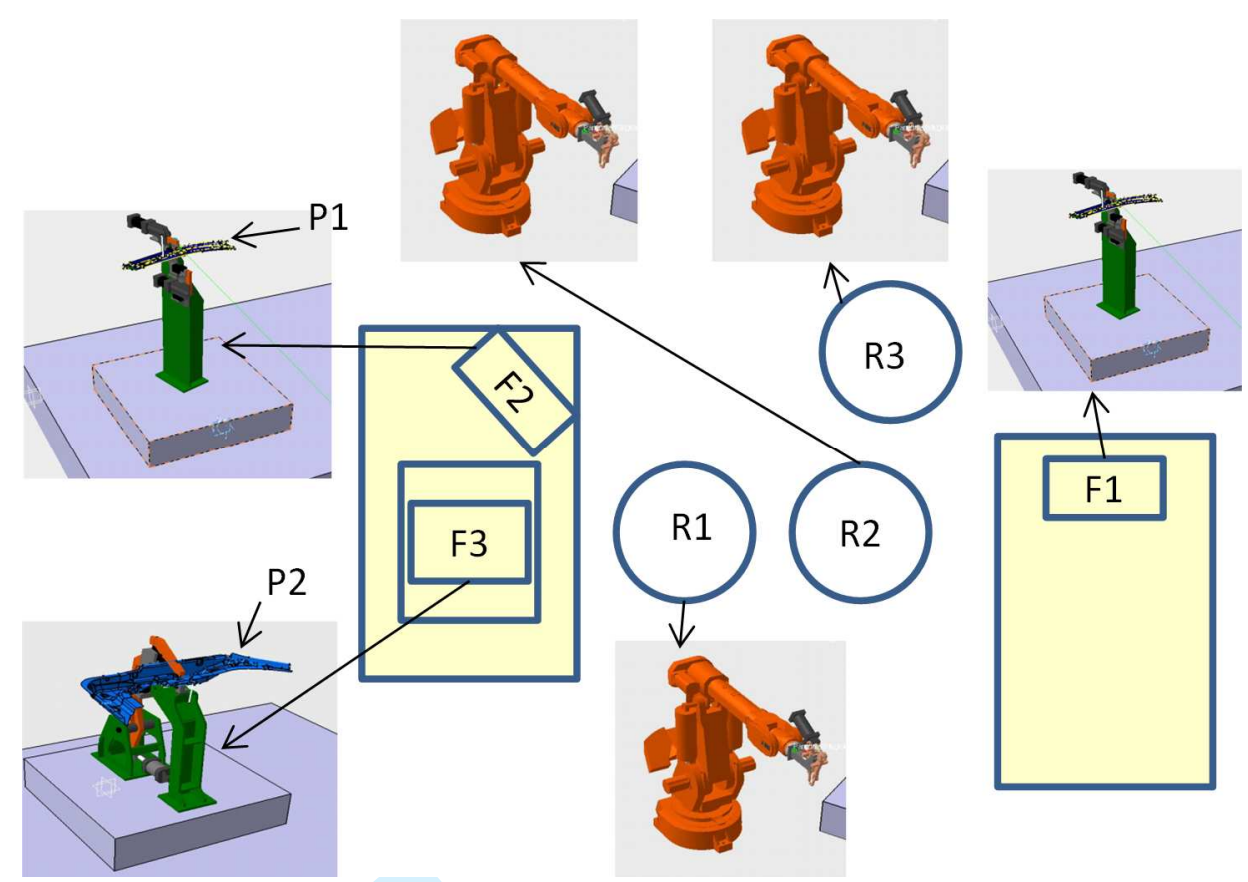

Figure 6. Layout of the fixtureless work cell (case B).

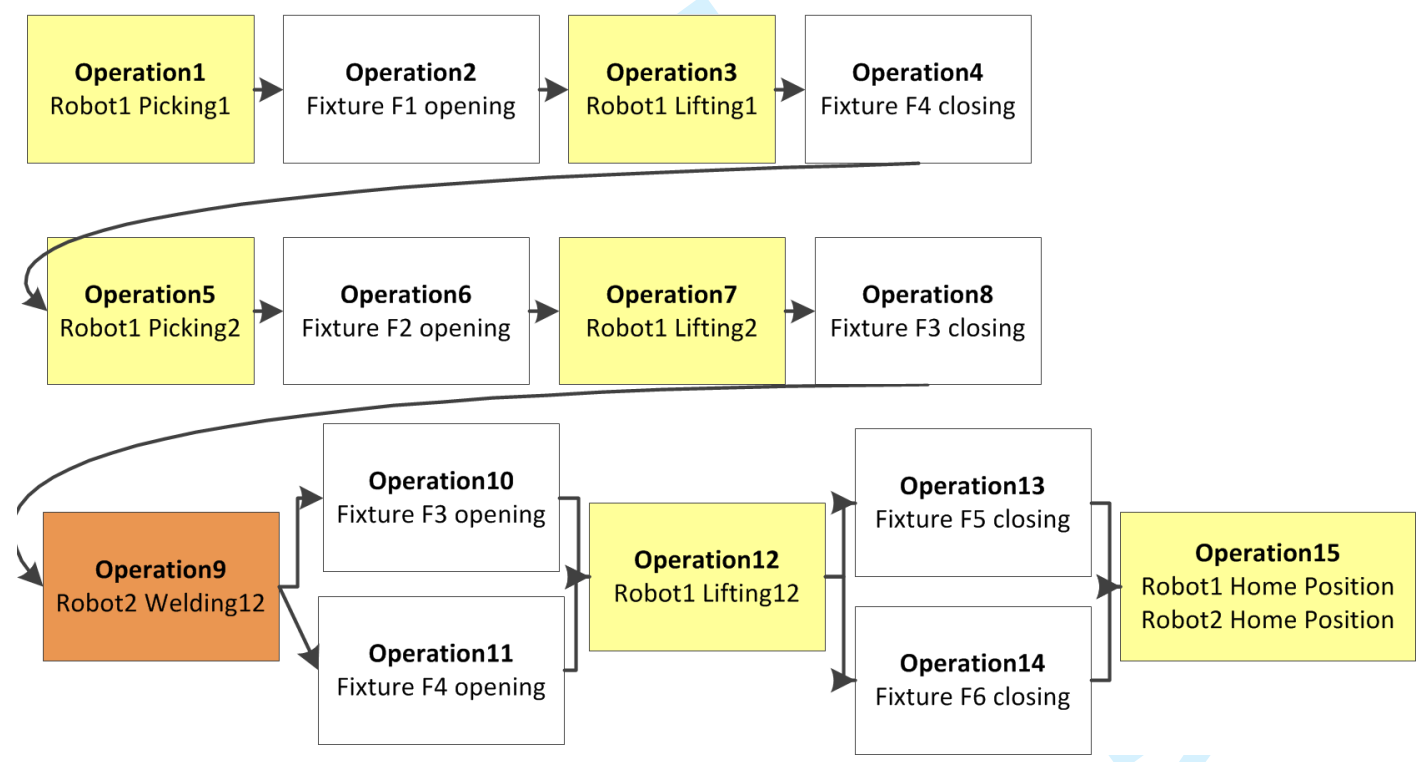

Figure 7. Sequence of operations carried out in case A (with reference to Figure 2). 




Figure 8. Sequence of operations carried out in case B (with reference to Figure 3).

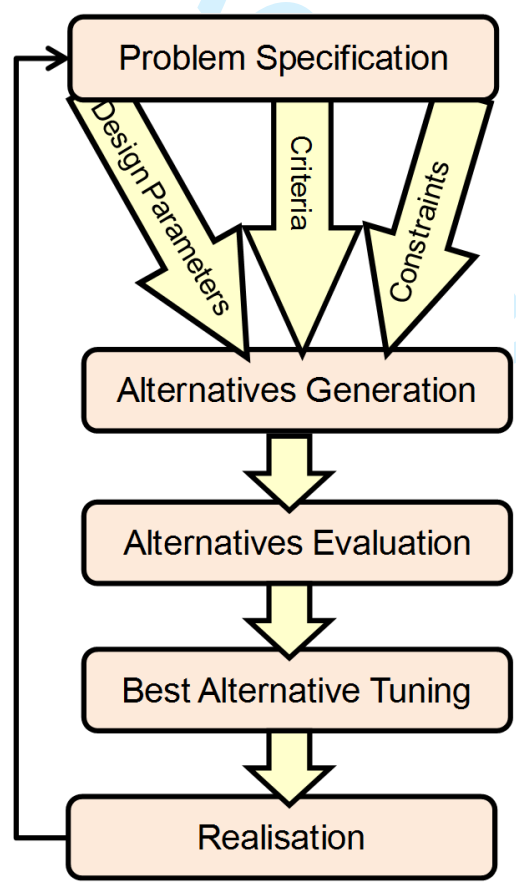

Figure 9. Generic robotic cell design process. 